\title{
A Literature Review on the Inheritance Model of Family Business
}

\author{
Kaiyan $\mathrm{He}^{*}$ \\ Accounting College \\ Guangdong University of Finance and Economics \\ Guangzhou Guangdong, China, 510320
}

\author{
Jintao Yan \\ Accounting College \\ Guangdong University of Finance and Economics, \\ Guangzhou Guangdong, China, 510320
}

\begin{abstract}
As a universal form of business organization, family business plays an important role in social and economic development. In the $\mathbf{4 0}$ years of reform and opening up, with the changes of the times and the age of the founders of a generation of family business, it is urgent to find a suitable successor for family business. This paper takes the family business inheritance mode as the research theme, through the analysis of the research on the intergenerational inheritance mode at home and abroad, finds that the intergenerational inheritance of Chinese family business can be divided into two ways: internal succession and external appointment of professional managers. On this basis, it analyzes the influencing factors of the choice of internal succession or external succession and the advantages and disadvantages of the two modes. At the same time, it puts forward the future research prospects of family business inheritance.
\end{abstract}

Keywords-family business; internal inheritance; external inheritance; influencing factors

\section{INTRODUCTION}

The inheritance of family business is an enduring topic. According to Wang Wenjing's (2010) report on the development of China's family enterprises, the proportion of family enterprises in private enterprises is more than $80 \%$, making a significant contribution to the development of the national economy. After the reform and opening up, the first generation of founders of Chinese family business gradually reached the age of retirement, and inheritance has become an unavoidable major issue. In China's family business, on the one hand, influenced by the traditional culture of our country, the inheritance of enterprise means the inheritance of family business, and business owners are more inclined to inherit the enterprise to their own people; on the other hand, under the background of economic globalization, the scale of family business is growing, The existing family members may not be able to effectively manage the enterprise, and the need to introduce foreign professional managers is growing. At present, the two main inheritance modes of family business are internal succession and external succession. Choosing the appropriate inheritance mode of family business is very important for the sustainable development of enterprises.

In view of the existing research, we find that some scholars think that internal inheritance is conducive to the development of enterprises, and some scholars support the view that professional manager succession model is conducive to the development of enterprises. Based on the analysis of the existing literature, this paper attempts to summarize how to choose the appropriate way of inheritance in different situations, and make some suggestions for the smooth implementation of family business shift.

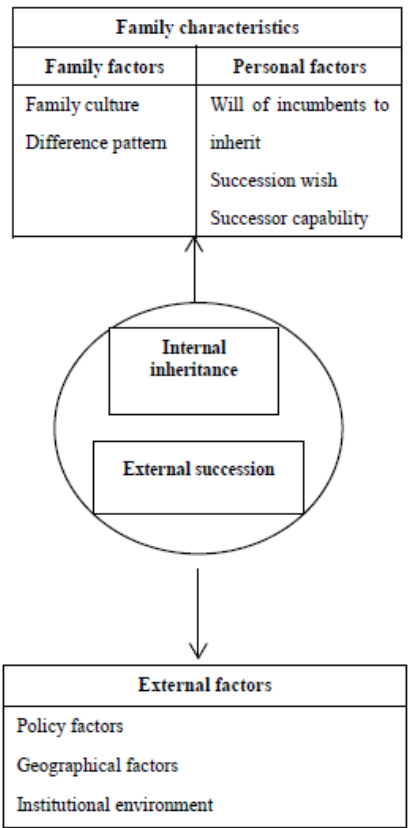

Fig.1. organizational framework

\section{THE INFLUENCE OF FAMILY INTERNAL FACTORS ON THE} INHERITANCE MODE OF FAMILY BUSINESS

\section{A. The influence of family organizational characteristics on family inheritance model}

Under the influence of Chinese traditional Confucian culture, the controlling family of the family business regards the business as "family business". The prosperity and development of the business is the embodiment of family glory. Keeping the control of the family business is not only the pursuit of economic interests, but also the pursuit of non-economic factors such as emotional factors. For business owners, it's their duty to conscientiously operate during the period of operation and management. After leaving office, they will pass on the career they've built all their lives to their children and pass on the enterprise as a family business for generations. For heirs, it's also their duty to maintain the family continuity and conscientiously carry forward the family 
business. In an enterprise with strong family culture atmosphere, external managers have a weak sense of existence and security. Their prestige in the enterprise is difficult or impossible to establish. At the same time, the sense of responsibility of external managers will be hit, resulting in their inability or lack of motivation to play their management functions. In this case, further reduce the willingness of enterprises to use external managers.

Based on the influence of family culture, differential order pattern and other factors, controlling family tends to inherit the enterprise to the internal personnel. Fei Xiaotong (1984) put forward the famous theory of differential order pattern, holding that under the influence of traditional Chinese culture, people pay attention to relationship network in the process of communication[1]. Fushan (1998) took the trust mode of family business as the research object, and found that the trust of Chinese family to internal personnel was significantly higher than that of external members .Wang Jianmin (2005) proposed that in the process of social development and transformation in China, with the convenience and frequency of social contact, we pay more and more attention to the communication with strangers. At the same time, the importance of building trust relationship with strangers is becoming more and more prominent, and our social circle is gradually spreading from acquaintances. Qian Haiting (2009) pointed out that in China's family businesses, enterprises reflect the characteristics of business trip sequence pattern in the way of selecting talents[2]. Jiao Kangle, Li Yanshuang and $\mathrm{Hu}$ Wangbin (2019) proposed that the adoption of internal or external inheritance of family businesses largely depends on the family businesses' attention to social emotional wealth[3].

\section{B. The influence of personal characteristics of incumbents and heirs on family inheritance model}

In the family business, the generation of entrepreneurs in the family business set up and developed the business under the background of reform and opening up. They have rich social experience and talent, and their entrepreneurial experience and success mode are unique and hard to copy. Their different experiences and characteristics will affect the planning of enterprise development prospects and their own evaluation. For the second generation heirs, on the one hand, the one-child phenomenon is more common, and the number of family heirs is small; on the other hand, whether the heirs have the confidence and ability to realize the development and expansion of the enterprise is an important factor affecting their willingness to take over. Because of the differences in education and living environment, the second generation's willingness to take over is different from person to person.

There is no doubt about the importance of the personal characteristics and life experience of the family incumbents and heirs to the enterprise inheritance. Such as Dou Junsheng (2006) proposed that the departure intention, personality and demand of the incumbent, the succession intention, ability and experience of the successor would have an impact on the corporate heritage. Huang Xiaoye (2007) believed that the incumbent in the family business is responsible for promoting the issues related to intergenerational inheritance, and his willingness is very important for the selection of inheritance mode. Tong Fang (2014) found that the turnover intention, personality, physical condition and self-awareness of incumbents will have an important impact on corporate heritage[4]. Li Xiujuan (2015) proposed that the willingness and ability of the second generation to take over were influenced by factors such as education level and preparation for taking over[5].

\section{THE INFLUENCE OF EXTERNAL FACTORS ON THE INHERITANCE MODE OF FAMILY BUSINESS}

\section{A. The influence of policy and geographical factors on the inheritance model of family business}

In addition to the influence of the family's internal conditions, regional policies and the industry in which the enterprise is located will also have an impact on the inheritance mode of the enterprise. Jerry Cao, Douglas Cumming, and Xiaoming Wang(2015) pointed out that the implementation of family planning policy makes the number of children of the founders of this generation less, reducing the goal of inheritable objects within the family[6]. On the one hand, the family planning policy improves the intimacy between parents and children and reduces the uncertainty of training objects; on the other hand, once the only child does not succeed or has no intention of inheritance, it is not conducive to the development of enterprises.

The influence of strong family concept on the governance of family business is different. In areas with strong family concept atmosphere, the willingness to transfer rights within the family is stronger, and in areas with weak family concept atmosphere, the founders will be less affected by family members when considering the issue of successors. For example, Xue Shengxi and Li Peigong (2017) used the regional divorce rate as an indicator to measure the concept of regional families, the study found that the lower the divorce rate, the lower the willingness of internal inheritance; the higher the divorce rate, the lower the willingness of founders to inherit the enterprise to family members[7]. In the case that the industrial model of the enterprise is centralized, the family management can meet the business management needs of the enterprise. If the enterprise adopts diversified development mode, it needs compound talents for enterprise management. For the enterprise, only the internal members of the family are afraid to be competent and need to introduce external professional talents.

\section{B. The influence of institutional environment on the inheritance model of family business}

Both individuals and enterprises exist in a certain social environment, and their behaviors and decisions are inevitably affected by various factors in their environment. Fan Gang, Wang Xiaolu, and Zhu Hengpeng(2011) proposed different marketization processes in different regions of China[8]. He Xuan et al. (2014) took China's private enterprises as the research object, and found that the institutional environment perception of family business owners was positively related to the family internal inheritance, and the adverse perception of the institutional environment would reduce the willingness of enterprise internal inheritance; however, the higher the political status of the family business owners, the weaker the influence 
of the adverse perception of the institutional environment on the inhibition of internal inheritance [9]. Li Xinchun (2003) pointed out that in the absence of an effective professional manager market, to a large extent; Chinese enterprises are facing more serious agency problems. On the one hand, family members are more likely to be senior managers than non-family members due to their family characteristics, which may lead to the lack of ability of family senior managers; On the other hand, the imperfect market of professional managers and the lack of relevant legal systems may lead to moral hazard and adverse selection of professional managers.

\section{CONCLUSION AND ENLIGHTENMENT}

\section{A. Conclusion}

At the beginning of the 21st century, family business has become the focus of scholars, and the inheritance of family business has become a major focus of domestic and foreign scholars. Based on the selection of family business intergenerational inheritance mode and its influencing factors, this paper makes a literature review. Generally speaking, the selection of internal succession or external inheritance is mainly influenced by the internal culture, personal characteristics of successors and incumbents, institutional factors and other dimensions. In terms of ability, the advantages and disadvantages of internal successors are more clear, the details of external professional managers need to take a long time to judge and measure, the external selection space is larger, and it is easier to find capable people; in terms of legitimacy, the internal successors have a stronger sense of life for the enterprise, including the natural sense of identity of the employees of the enterprise to the internal successors of the family.

1) Most of the entrepreneurs will strive to balance family affection and ability. If family members are able and willing to take charge of business affairs, they tend to adopt the way of internal inheritance to carry out succession. In the small family business, the management level is less, things are simpler, the requirements for managers are relatively low, and the internal succession mode is mainly adopted. In the small family business, the management level is less, things are simpler, the requirements for managers are relatively low, and the internal succession mode is mainly adopted;

2) In the absence of suitable family members or insufficient ability of family members, we choose to separate the inheritance of family from the inheritance of family business. Family members inherit the ownership and actual control rights, and introduce professional managers to take important positions in the enterprise to be responsible for the operation and management of the enterprise.

3) Considering the changes of external environment factors, in the case of strong family culture atmosphere or slow development of system environment, the way of choosing internal personnel to take over in family business is helpful for successors to gain the recognition of enterprise and society, and make up for the instability of enterprise development caused by imperfect system.

\section{B. Enlightenment}

1) Avoid copying the model or conclusion of family inheritance in foreign literature. The choice of family inheritance mode, the family business of our country is deeply influenced by Chinese traditional culture; we need to consider the influence of Chinese characteristic culture on inheritance.

2) When making decisions, we should pay attention to the potential role of the external environment. With the rapid economic development of China, the development level of each region is quite different, and the geographical environment creates different local characteristics. Various external factors play an important role in the inheritance of enterprises.

3) In combination with the actual situation of the enterprise, we should attach importance to inheritance. Family business as a rapid development in the reform and opening up of the organizational form, practical evidence shows that it is reasonable. Inheritance means that the next leader takes over the management right of the enterprise and is responsible for the management decision of the enterprise. There are advantages and disadvantages for family business to choose external succession or family member succession to complete the power handover. The inheritance of family business should be considered together with the development of family business, and the appropriate way should be selected in combination with its own reality.

\section{REFERENCES}

[1] Fei Xiaotong. Local China [M]. Shanghai: Shanghai Sanlian bookstore, 1985 . (In Chinese).

[2] Qian Haiting. Analysis of employment mode of family business [J]. Journal of northwest agricultural and Forestry University of science and Technology (SOCIAL SCIENCE EDITION), 2009, 09 (5): 63-66. (In Chinese).

[3] Jiao Kangle, Li Yanshuang, Hu Wangbin. Study on the selection motivation of family business inheritance mode based on the perspective of social emotional wealth [J]. Economic management, 2019,41 (01): 71-88. (In Chinese).

[4] Tong Fang. Study on main influencing factors and Countermeasures of intergenerational inheritance of family enterprises in China [D]. Shijiazhuang Railway University, 2014. (In Chinese).

[5] Li Xiujuan. Returning to family culture: how to improve the willingness to take over [J]. Tsinghua management review, 2015 (12): 32-41. (In Chinese).

[6] Jerry Cao, Douglas Cumming, Xiaoming Wang. One-child policy and family firms in China [J]. Journal of Corporate Finance, 2015, 33:317-329.

[7] Xue Shengxi, Li Peigong. Family culture, CEO change and corporate financial behavior [J]. Journal of Shanxi University of Finance and economics, 2017,39 (06): 101-112. (In Chinese).

[8] Fan Gang, Wang Xiaolu, Zhu Hengpeng. China's marketization index: relative process of marketization in various regions 2011 report [M]. Economic Science Press, 2011. (In Chinese).

[9] He Xuan, Song Lihong, Zhu Kang, Li Xinchun. Why does the family want to let go? -- perception of institutional environment, political status and inheritance willingness of Chinese family business owners [J]. Management world, 2014 (02): 90-101 + $110+188$ 